\title{
A construção do discurso dos sujeitos envolvidos com o processo de reforma psiquiátrica:

\author{
um estudo sobre o município de Joinville/SC*
}

Maria Lúcia da Silva Bueno'

Sandra Caponi

BUENO, M.L.S.; CAPONI, S. Discourse construction among subjects involved in the process of psychiatric reform - a study on the municipality of Joinville, Santa Catarina. Interface - Comunic., Saúde, Educ., v.13, n.28, p.137-50, jan./mar. 2009.

This paper aimed to put into place the discourse of the subjects involved in the psychiatric reform process in the municipality of Joinville, Santa Catarina. The discourse and practices needed to be elucidated and revealed because knowledge is constructed and realities are transformed in daily practice. Qualitative investigation of case study type was the methodological route, and it was carried out by means of open interviews with a semistructured script. The subjects involved contributed their experiences and reflections through expressing their opinions and convictions about the current process. The final considerations, based on discourse analysis, indicated some criticisms: the discourse was sometimes more controversial and political and sometimes more conservative and traditional, thus revealing a certain degree of bias and reductionism in the process. Nonetheless, new spaces are being occupied, and some professionals' practices have been transformed.

Key words: Psychiatry. Mental Health. Discourse analysis.
Pretende-se situar o discurso dos sujeitos envolvidos no processo de Reforma Psiquiátrica no município de Joinville/SC. Os discursos e as práticas necessitam ser elucidados e desvelados, pois na práxis cotidiana se constrói o conhecimento e se transforma a realidade. Como caminho metodológico utilizamos a pesquisa qualitativa, tipo estudo de caso, realizada por meio de entrevista aberta com roteiro semiestruturado. Os sujeitos envolvidos contribuíram com suas experiências e reflexões expressando suas opiniões e convicções quanto ao processo em curso. As considerações finais, baseadas na análise de discurso, apontam críticas pontuais, ora são mais polêmicas e políticas, ora são mais conservadoras e tradicionais, revelando um certo enviesamento e reducionismo do processo, porém novos espaços vêm sendo ocupados e as práticas de alguns profissionais têm se alterado.

Palavras-chave: Psiquiatria. Saúde Mental. Análise de discurso.

\footnotetext{
* Artigo elaborado com base em Bueno (2006). ${ }^{1}$ Assistente social. Secretaria Municipal de Joinville. Rua Águia, 168, Bairro Costa e Silva, Joinville, SC, Brasil. 89.220-140 malubueno2@gmail.com ${ }^{2}$ Filósofa. Departamento de Saúde Pública, Universidade Federal de Santa Catarina.
} 


\section{Introdução}

Este artigo tem por objetivo situar o discurso dos sujeitos envolvidos com o processo de Reforma Psiquiátrica no município de Joinville/SC, apresentando, assim, parte dos resultados da pesquisa realizada no período de 2005 a $2006^{3}$. Como caminhos metodológicos, optamos pela pesquisa qualitativa, utilizando o estudo de caso, buscando compreender como e por que se constrói o discurso dos sujeitos. $O$ instrumento utilizado para coleta de dados foi a entrevista aberta com roteiro semiestruturado ${ }^{4}$, possibilitando a participação comunicativa e permitindo ao entrevistado falar da percepção, da vivência e da práxis do seu cotidiano, procurando, assim, dar visibilidade ao discurso que permeava a práxis e o saber dos sujeitos (Gill, 2002; Minayo, 2000).

Os sujeitos - usuários e profissionais entrevistados - totalizaram dez participantes ${ }^{5}$, os quais foram esclarecidos e orientados quanto ao propósito da pesquisa. As entrevistas foram gravadas, transcritas e revistas pelos participantes, os quais assinaram o termo de consentimento livre e esclarecido, conforme aprovação do Comitê de Ética em Pesquisa da UFSC.

As falas foram analisadas com base na análise de discurso, apreendendo, ou seja, extraindo o sentido e a ideologia que as falas trazem em si, pois as mais simples palavras utilizadas no cotidiano chegam até nós carregadas de sentidos, os quais não sabemos como se constituíram e o que representam em nós e para nós. Como propõe Orlandi (2000, p.38), " todo o dizer é ideologicamente marcado, é na língua que a ideologia se materializa num espaço regido pela simbolização das relações de poder como dissemos, o discurso é o lugar do trabalho da língua e da ideologia".

Logo, deve-se observar: de que lugar fala esse sujeito, qual papel ocupa, como se posiciona frente ao seu interlocutor, e quais imagens de poder ambos fazem um do outro, pois essas são socialmente construídas. Salienta a autora que "o imaginário faz necessariamente parte do funcionamento da linguagem. Ele é eficaz. Ele não brota do nada: assenta-se no modo como as relações sociais se inscrevem na história e são regidas, em uma sociedade como a nossa, por relações de poder" (Orlandi, 2000, p.42).

A autora reforça que um dos pontos fortes da análise de discurso "é resignificar a noção de ideologia a partir da consideração de linguagem" (Orlandi, 2000, p.45), pois não existe sujeito sem história, nem discurso sem sujeito e nem sujeito sem ideologia.

Assim, toda interpretação é regulada em suas possibilidades, em suas condições, não sendo mero gesto de decodificação, ou apreensão de sentidos. Deve-se considerar que "nem a linguagem, nem os sentidos, nem mesmos os sujeitos são transparentes: eles têm sua materialidade e se constituem em processo em que a língua, a história e a ideologia concorrem conjuntamente" (Orlandi, 2000, p.48); por isso, optamos por analisar os discursos utilizando esse referencial.

Contextualizando o município de Joinville/SC, convém pontuar que possui uma rede de atenção em saúde mental descentralizada, implementada desde os idos de 1988 e, atualmente, com nove sedes regionais de saúde, as quais contam com os seguintes profissionais: enfermeiros, médicos generalistas e especialistas, técnicos administrativos e de enfermagem, agentes de saúde pública e comunitário de saúde; e uma equipe específica de saúde mental com: psiquiatra, psicólogos e terapeuta ocupacional, os quais interagem com os demais profissionais fazendo o matriciamento das equipes de saúde da família e postos de saúde de sua adscrição.
${ }^{3}$ A qual faz parte da dissertação do mestrado em Saúde Pública pela Universidade Federal de Santa Catarina/UFSC.

${ }^{4}$ As perguntas foram elaboradas considerando as seguintes questões: 0 que se entende por loucura, doença mental, reforma psiquiátrica, desinstitucionalização. O que identificavam como ações que apontam para o reforma psiquiátrica; e como se dá a relação interdisciplinar na equipe de trabalho e se percebe

questionamentos quanto à desconstrução do modelo asilar e os conceitos da psiquiatria tradicional.

\footnotetext{
${ }^{5}$ Ressaltamos que os profissionais entrevistados, no total de sete, foram escolhidos de forma aleatória (sorteio); todos são servidores públicos, cinco deles com mais de dez anos de prestação de serviços em saúde mental, e dois com aproximadamente três anos. Todos conheciam o modelo asilar

(profissional-estagiários) e estavam, no momento, prestando serviços na rede de atenção psicossocial do município (sede de Regional de Saúde, Centro de Atenção Psicossocial, Pronto Acolhimento Psicossocial, Serviços Organizados de Inclusão Social), representando, assim, as categorias profissionais (agentes de saúde, assistentes sociais, psicólogos, psiquiatras, e terapeutas ocupacionais) que atuam nas referidas equipes. Quanto aos usuários entrevistados, no total de três, foram escolhidos entre os que haviam passado por mais de 15 internações em hospitais psiquiátricos $\mathrm{e}$ estavam em atendimento em serviços substitutivos da rede de atenção em saúde mental (CAPS e SOIS).
} 
${ }^{6}$ Conforme portaria 336/ GM/2002 do Ministério da Saúde. O CAD/CAPS II atende a população do município, $500 \mathrm{mil}$ habitantes, e têm como missão oferecer atenção psicossocial, evitar internações psiquiátricas, articular e dar suporte à rede de atenção em saúde. Realiza atendimento intensivo, semi-intensivo e não

intensivo diuturnamente, de segunda a sextasfeiras, das 7:00 hs às 18:00 hs, atualmente com referência de miniequipe para cada território adscrito, os quais fazem matriciamento das equipes de saúde mental das regionais.

${ }^{7}$ Em 2002 implanta-se o CAPS a d (álcool e drogas), que funciona diuturnamente, de segunda a sextas-feiras, das 7 h00 às 20h00. E em 2005 constituiu-se o Serviços Organizados de Inclusão Social (SOIS) que prioriza a clientela dos CAPS e regionais de saúde, enfocando a

inclusão pelos pilares da convivência, geração de renda, educação e moradia. Já em 2006, organiza-se o CAPS i

(infantil) que funciona diuturnamente, de

segunda a sextas-feiras, das 7 h00 às $18 \mathrm{~h} 00$.

Conta, ainda, com um Pronto Acolhimento Psicossocial (PAPS), o

qual acolhe a demanda em saúde mental e encaminha conforme

cada situação (PAPS que este ano está fazendo

dez anos); e a Associação

de Recuperação para o

Trabalho (REPART), que

prioriza a geração de renda, sendo esta

organizada para ser uma

referência aos usuários e familiares, neste ano completa 15 anos. Convém ressaltar o recente processo de cadastramento e

implantação do CAPS III

Dê-Lírios, o qual tem

hospitalidade 24 horas

inclusive nos finais de semana (set/2008)
Um dos marcos para a saúde mental de Joinville foi a implantação, em 2001, do serviço substitutivo à internação psiquiátrica, conhecido como Centro de Atenção Diária "Nossa Casa" (CAD), o mesmo que um CAPS II'. Com a implantação de outros dispositivos, a rede vem se constituindo de forma sólida ${ }^{7}$, mostrando que é possível garantir: a atenção psicossocial, a inclusão, o acolhimento, o suporte na crise e os princípios que norteiam o SUS.

Destacamos que, no município, não há hospital psiquiátrico. As emergências em saúde mental são atendidas no Pronto Socorro do Hospital Regional Hans Dieter Schmidt, o qual dispõe de uma unidade de psiquiatria com 32 leitos psiquiátricos, sendo esse um hospital geral sob gerência do Estado.

O processo de construção da rede em atenção psicossocial em Joinville tem suas marcas, suas conquistas e, também, seus impasses/retrocessos. Citamos, por exemplo, a não existência de uma coordenação municipal em saúde mental, sendo que os CAPS estão subordinados à gerência de referências; e, também, que as ações de saúde mental na atenção básica estão sob gerência da mesma, o que fragmenta a interlocução e trocas, pulverizando o papel dos CAPS e deixando, nas sombras, o desenho político, o planejamento da saúde mental, enfim, a coordenação político-institucional. Outras dificuldades são: o atendimento em situações de crise e controle dos leitos sob gerência do Estado, e a falta de apoio no resgate das urgências/emergências, haja vista constantes conflitos com o Serviço de Atendimento Móvel de Urgência (SAMU), também sob gerência do Estado. Outro impasse que denota as deficiências da rede é a falta de residência terapêutica, por isso alguns usuários permanecem ocupando leitos de longa permanência, em hospitais psiquiátricos do Estado de Santa Catarina.

Sendo assim, os resultados ora apresentados fazem parte da realidade do município de Joinville-SC, o que nos remete a contornos de discursos que poderão vir a ser encontrados em outros municípios que passam pelo mesmo processo.

\section{Reforma Psiquiátrica: \\ a busca por outro lugar social para a loucura}

A história do tratamento do louco, da pessoa acometida por sofrimento mental no Brasil, nos leva a recorrer a um passado inóspito, sombrio e segregador. A trajetória da psiquiatria brasileira, modelo asilar, demarcou o lugar do louco, o do doente mental tutelado, com seus direitos sequestrados e sua cidadania interditada.

As experiências e tentativas de reformas psiquiátricas são variadas e diferenciam-se em conceitos, práticas e abordagens, trazendo em seu bojo a possibilidade de transformação, pois tudo o que é socialmente construído pode ser desconstruído e reconstruído novamente.

No Brasil, este processo recebe a influência das experiências acumuladas, que ocorreram na Inglaterra, França, Estados Unidos e Itália, e tem um marco fortalecido pela luta social de democratização do país.

Rotelli, Leonardis e Mauri (2001) ressaltam que as reformas psiquiátricas na Europa buscavam superar gradualmente a internação nos manicômios e criar novos serviços substitutivos na comunidade; porém, o processo enviesado de desinstitucionalizar acabou tendo a desospitalização como resultado, reduzindo sua abrangência. Eles pontuam: que as internações psiquiátricas, nessa proposta, continuam a existir como recurso terapêutico; que os serviços territoriais ou de comunidade convivem com a internação, não as substituem, mas confirmam sua necessidade, pulverizando o atendimento entre diversos serviços, que acabam fragmentados e especializados. 


\begin{abstract}
A intenção de liberar a Psiquiatria (e o seu objeto) da coação e da cronicidade que esta produzia para restituir-lhe o estatuto terapêutico resultou na construção de um sistema complexo de prestações que, reproduzindo e multiplicando a lógica somente negativa da desospitalização selecionam, decompõem, não se responsabilizam, abandonam. É razoável reter que este é um projeto impossível, mas que através dessas operações tenta-se fazê-lo parecer real. (Rotelli, Leonardis, Mauri, 2001, p.24)
\end{abstract}

Tendo como via a desospitalização, este modelo buscou desinstitucionalizar a necessidade de coação e dos lugares de internação, "eles permanecem e se confirmam como um elemento necessário ao funcionamento do sistema" (Rotelli, Leonardis, Mauri, 2001, p.24).

A proposta de desconstrução da instituição manicomial e asilar perpassa as relações administrativas e interpessoais, exigindo a transformação cultural de todos os atores sociais envolvidos. Ele defende que a "desinstitucionalização é, sobretudo, um trabalho terapêutico, voltado para a reconstituição das pessoas, enquanto pessoas que sofrem, como sujeitos. Talvez não se resolva por hora, não se cure agora, mas no entanto seguramente se cuida" (Rotelli, 2000, p.33).

As análises históricas desse processo em curso no Brasil podem ser encontradas em seus variados matizes e paradigmas, porém os autores são unânimes em afirmar sua complexidade, diversidade, confrontos e conflitos teóricos e políticos ${ }^{8}$.

Para Tenório (2002), o reclame da cidadania do louco vem sendo a marca distintiva e fundamental da reforma, "a importância analítica de se localizar a cidadania como valor fundamental e organizador desse processo, está em que a reforma é, sobretudo, um campo heterogêneo, que abarca a clínica, a política, o social, o cultural e as relações com o jurídico, e é obra de atores muito diferentes entre si" (Tenório, 2002, p.28).

Conforme Amarante (2003b), a Reforma Psiquiátrica se propõe a romper com o estigma de se compreender o louco como o ser tutelado, indesejável e dependente; que o louco não é uma pessoa sem razão e sem juízo, mas sim um sujeito, defendendo "que os princípios éticos desta Reforma perpassam a inclusão, a solidariedade e a cidadania" (p.58). Ressalta que a psiquiatria "é apenas uma disciplina, dentre tantas outras, que pode contribuir parcialmente para explicar e intervir sobre o fenômeno da loucura" (p.61).

Corroboramos com Amarante (2003a) que a Reforma Psiquiátrica brasileira é um processo social complexo, em movimento, em construção, uma reforma da e para a saúde mental, o qual precisa ser elucidado e pesquisado, para que possamos conhecer e compreender os meandros e as bases científicas que o legitimam. Para o referido autor, no bojo mais profundo desse processo de reforma psiquiátrica, existem peculiaridades que exigem uma adjetivação precisa, por ser considerado um processo histórico de formulação crítica e prática, tendo como objetivos e estratégias: o questionamento e a elaboração de propostas de transformação do modelo clássico, do paradigma epistêmico da psiquiatria.

A psiquiatria foi fundada num contexto epistemológico em que a realidade era considerada um dado natural, capaz de ser apreendido, revelado, descrito, mensurado e comparado, nasceu em um contexto em que a ciência significava a produção de um saber positivo, neutro, autônomo: era a expressão da verdade! (Amarante, 2003a, p.55)

\author{
${ }^{8}$ Ressaltamos que \\ Amarante (2003c), em \\ "O Homem e a \\ Serpente", aprofunda a \\ compreensão sobre o \\ processo de reforma \\ psiquiátrica entendido \\ como \\ desinstitucionalização/ \\ desospitalização/ \\ desconstrução, mas \\ optamos focar a análise \\ partindo das dimensões \\ existentes no processo \\ social complexo de \\ reforma psiquiátrica, \\ conforme defende $o$ \\ mesmo autor em \\ Amarante $(2007,2003 a)$. \\ Sugerimos consultar os \\ seguintes autores que \\ aprofundam tal análise: \\ Paulim (2004); Desviat \\ (2002); Portocarrero \\ (2002); Tenório (2002); \\ Amarante $(2000,1994)$.
}


Destaca o autor que, nesse processo, existem interesses conflitantes e negociações acontecendo simultaneamente; que não dispomos de teoria que dê conta de descrever plenamente os fatos, e que:

Se configura na e pela articulação de várias dimensões que são simultâneas e inter-relacionadas, que envolvem movimentos, atores, conflitos e uma tal transcendência de objeto de conhecimento que nenhum método cognitivo ou teoria podem captar e compreender em sua complexidade e totalidade. (Amarante, 2003a, p.49)

Esse processo social complexo pode ser compreendido pelas seguintes dimensões, conforme Amarante (2003a): teórico-conceitual, sociocultural, técnicoassistencial e jurídico-política. Essas dimensões precisam ser aprofundadas e desmistificadas, visto que o conhecimento acumulado construído no contexto da psiquiatria traz um cientificismo naturalista, biologicista, revelando que esta concepção de ciência é arraigada na formação e visão dos profissionais da área.

Para alguns autores e atores sociais, a reforma é entendida como sinônimo de reestruturação ou modernização de serviços, ou seja, simples reformulação técnicoassistencial, 'capsização' do modelo assistencial e 'inampsização' do modelo de financiamento, o que Amarante (2003a) denuncia como desvios graves de descaracterização do processo social complexo.

Alguns autores entendem que esse processo social complexo passa, também, por outro objetivo, que é o da construção de um outro lugar social para a loucura, o que demanda a transformação das relações da sociedade com a loucura e da relação estabelecida pelo saber/poder da psiquiatria e das demais disciplinas (Amarante, 2003a; Birman, 1994).

Como compreender tal processo em desconstrução, perpassado em suas variadas

${ }^{9}$ Sugerimos a leitura de Amarante (2007), onde o autor resgata e aprofunda as dimensões existentes no processo social complexo do campo da saúde mental para além da psiquiatria.

${ }^{10}$ Os nomes utilizados são fictícios, para resguardar os participantes.

Destaques em suas falas encontram-se em negrito e interferência da pesquisadora em sublinhado. Convém salientar que em média cada participante contribuiu

aproximadamente com quarenta minutos de entrevista.

Agradecemos a estes a contribuição e permissão para publicização de seus discursos. dimensões teórico-conceitual, sociocultural, técnico-assistencial e jurídico-política ${ }^{9}$ ? Como enfrentar o cotidiano da práxis sem compreender a subjetividade da loucura em sua complexidade teórica, sociológica, antropológica e política? (Alverga, Dimenstein, 2005); como os novos técnicos assumem sua práxis se parece haver um interdito, um negar a história de segregação e modelo asilar? (Lobosque, 2006; Saraceno, 2001).

Então, cabe-nos perguntar: que discurso vem tendo a primazia entre os atores sociais envolvidos nesse processo social complexo de Reforma Psiquiátrica, no município de Joinville/SC?

\section{A compreensão do processo de Reforma Psiquiátrica em Joinville/SC}

Enfocaremos algumas falas dos sujeitos envolvidos nesse processo, discursos carregados de significados e sentidos, pois se modificam e se movimentam com o sujeito, pois falamos com palavras que já foram ditas, mas o discurso não está pronto e acabado, como esclarece Orlandi (2000, p.37): "que a incompletude é a condição de linguagem: nem sujeitos nem os sentidos, logo, nem o discurso, já estão prontos movimento do simbólico e da história".

Os discursos pontuados a seguir nos contam como alguns trabalhadores da rede de atenção em saúde mental de Joinville/SC, com base nas suas experiências pessoais e no envolvimento ou não com o processo de Reforma Psiquiátrica ou de Luta Antimanicomial, percebem esse processo. Vejamos a fala da psicóloga Acácia ${ }^{10}$, que diz ter sido influenciada na graduação, e que percebia certa discussão referente à Reforma Psiquiátrica: "Já no meu período de formação a gente tinha uma postura e acabados. Eles estão sempre se fazendo, havendo um trabalho contínuo, um 
muito crítica dos nossos métodos e nossas técnicas, do que estava sendo feito, entende? Eu entrei na universidade, coincidentemente era uma época que as coisas já estavam com relação à reforma psiquiátrica borbulhando!!" (Psicóloga Acácia).

A profissional Camila lembra dos primeiros passos do movimento de luta antimanicomial e demonstra sua satisfação por ter participado inicialmente, inclusive do momento que motivou a comemoração do dia nacional de luta antimanicomial. Ressalta que sua participação aconteceu sem que ela tivesse plena consciência e convicção do alcance do que estavam fazendo, era puro idealismo, acreditava nas mudanças, e não queria aquele modelo asilar.

Então aquela coisa de estar em passeata, de ir atrás, e tinha aquilo de muito idealismo, e de conhecimento concreto talvez sobre tudo isto, tinha pouco, isto era uma coisa em movimento, era um cara pintada que fizeram, um negócio que eu só tinha uma noção assim, que eu não queria que o modelo fosse aquele do Juquery, isto eu tinha claro pra mim, que aquele modelo não era o modelo que deveria ser...porque era terrível, não dá nem pra sonhar com aquilo lá de tão horrível. (Terapeuta Ocupacional Camila)

Para as profissionais Acácia e Suzana, o foco era a implantação de um modelo de atenção descentralizado por regional, buscando viabilizar o tratamento fora do hospital psiquiátrico, pensando um modelo de atenção voltado para a comunidade, a liberdade, e não o confinamento das internações psiquiátricas vigentes na época.

Estava tudo centralizado no INAMPS, que levava os pacientes para internação em Curitiba, não batia na prefeitura! Com a municipalização aí a prefeitura tinha que dar conta dessas questões todas, aí sim que água começou a bater! Os pacientes sem surtos começaram a vir, mas gente também já está com essa proposta de descentralizar nas regionais... (Psicóloga Acácia)

Nós viemos da mesma universidade ${ }^{11}$, já com essa lógica de luta antimanicomial, ou de uma tentativa de tirar o foco do tratamento da doença mental de dentro do hospital e colocar assim esses tratamentos nos postos de saúde, tirando essa óptica hospitalar, já pensando nisso na questão descentralizada. (Psicóloga Suzana)

O município de Joinville teve o privilégio de contar com esses e outros profissionais de formação mais crítica, que resistiam à construção de hospital psiquiátrico, e direcionavam a organização da rede de assistência de forma descentralizada, buscando a integralidade das ações de saúde, a promoção e a prevenção da doença/saúde mental.

Outros profissionais entrevistados, em seus discursos apontam para a organização do modelo e as falhas administrativas, referindo-se à reforma psiquiátrica como a programas, os quais atuam em diferentes frentes e necessidades, com certa humanização, sem, contudo, referenciar a abrangência do processo:

Pelo o que eu consigo perceber Joinville está bem dentro desde contexto da reforma e luta antimanicomial, até porque a internação aqui é somente em casos de surtos, casos agudos, a

1 Unesp, Universidade Estadual de São Paulo, em meados dos anos de 1985. 
maneira normalmente encaminhada para tratamento são nos Postos de Saúde, ou no CAD, procurando não afastar a pessoa de dentro da sua família, de uma maneira mais humana de tratamento. É uma busca cada vez maior para humanização do tratamento das pessoas. (Agente de Saúde Amália)

Eu acho que existem vários programas, eu acho que o CAD é um desses programas, que beneficia os pacientes, tentando evitar uma internação psiquiátrica, tentando a recolocação no mercado de trabalho, a REPART que é um outro programa, o SOIS (Serviços Organizados de Inclusão Social) que está sendo criado agora também... eu acho que todos esses programas novos são uma evolução pra Joinville dentro da saúde mental, no tratamento do doente mental. (Assistente Social Kely)

As falas acima são significativas e representativas de quanto o processo de Reforma Psiquiátrica vem sendo entendido como um processo restrito à reorganização de serviços, reestruturação do modelo assistencial psiquiátrico mais humanizado, à implementação de técnicas e programas. Isso remete a uma reforma de reparos, a uma reforma de aparências, negando-se assim, muitas vezes, sua complexidade, o que reduz o processo social complexo a simples e mera reestruturação dos serviços.

Se tanto autores quanto técnicos consideram o que se denomina por reforma psiquiátrica como um processo restrito à reorganização de serviços, vinculando-a a pura reestruturação do modelo assistencial psiquiátrico, pode-se concluir, em outras palavras, que consideram reforma psiquiátrica sinônima de modernização das técnicas terapêuticas. É comum, ainda, ver-se considerá-la como humanização das características violentas e perversas da instituição asilar, o que constitui uma luta e uma transformação muito importantes, mas que certamente reduz a amplitude de processo de questão. (Amarante, 2003a, p.46)

Outros dois profissionais, partindo de suas experiências, apontam mais os resultados atuais desse movimento, o que conseguem ver e acompanhar no município e na participação em encontros, congressos e revistas, relatando que:

A reforma é maravilhosa, então nesta experiência eu pude ver e dizer que bárbaro que é isso, que é a gente evoluir, que bárbaro para o profissional e para o paciente. (Psiquiatra Cléo)

Cada um tem a sua opinião, em relação a esta reforma, na verdade nem todo mundo é antimanicômio. [...] mas, claro que se você quiser acabar com os manicômios, significa fazer o que com uma população que necessita, hoje, nós não sabemos o que fazer com ela...

Crescendo o número de CAPS, de processos que permitem estes cuidados intermediários, que antes não tinha, ou ele estava internado ou ele estava no ambulatório, se meio descompensado, internou. (Psiquiatra Geraldo)

O profissional Geraldo demonstra ter certa reserva quanto ao processo de reforma, pois entende que não será possível ficar sem o recurso da internação, pois em sua prática cotidiana percebe ter uma parcela que necessita deste recurso sempre e que há uma lacuna na política organizada em Joinville. Ele reforça a importância dos CAPS, mas entendendo-os como serviços intermediários, e não substitutivos à internação. Isso revela certa resistência, por parte dos médicos psiquiatras, parcela essa muito temerária do possível fechamento dos hospitais, pois "o manicômio" permanece no mesmo papel de controle e ajustamento social, e a psiquiatria, a ciência que o legitima, endossada por outras tantas disciplinas.

Buscando compreender esse processo, alguns profissionais mantêm a centralidade do discurso na internação, no hospital psiquiátrico, como se fosse de fato impossível substituí-los, vejamos: 
Eu vejo que estão melhorando, principalmente, para os pacientes em termo do tratamento, de atendimento, isso diminui a internação, tem pacientes que nunca internaram e hoje em dia continuam sem internação, agora situações graves, no sentido de terem loucuras... as esquizofrenias, estas coisas, são pacientes fregueses do manicômio, os que mais possivelmente vão acabar dentro de hospitais psiquiátricos, se você não tiver um atendimento adequado. (Psiquiatra Geraldo)

\begin{abstract}
A gente vai ter pacientes que vão ter necessidade de uma internação mesmo de curto prazo, que estão psicóticos. O que a gente tem de leito não dá conta, em termos de população, a gente sabe que precisaria de um pouco mais, e aí a gente acaba retroagindo tendo que mandar um paciente para o hospital num modelo antigo ainda, ter mais centro diário de atendimento, acho que falta coisas do modelo, pensão protegida para os pacientes. (Psiquiatra Cléo)
\end{abstract}

A questão da internação psiquiátrica e o número de leitos vêm à tona, o hospital termina sendo a referência inevitável. Faltam "as coisas do modelo", faltam os dispositivos e equipamentos sociais que garantam a desinstitucionalização ${ }^{12}$ e que promovam essa proposta, que vai muito além de somente desospitalizar ou internar.

Como bem salientam Rotelli, Leonardis e Mauri (2001), em algumas propostas, o processo de Reforma Psiquiátrica é entendido como desospitalização, tendo como marca os lugares de internação e a necessidade de coação e controle.

Alguns profissionais continuam centrados no modelo asilar, onde a internação acaba sendo o lugar privilegiado de tratamento. Se há falhas na rede de atenção, essas são apontadas a partir da falta de leitos psiquiátricos; entretanto, o que há de fato é um viés de compreensão do processo em si, e uma posição ideológica marcada, a qual entende ser fundamental e necessário o hospital psiquiátrico em detrimento de outros dispositivos, como: CAPS III, residências terapêuticas, centros de convivência, cooperativas, oficinas de geração de trabalho e renda, entre outros.

Coexiste, então, certa dualidade. Ao mesmo tempo em que não querem o hospital psiquiátrico e percebem que o modelo de atenção psicossocial evita internações, defendem a necessidade de mais leitos, sem focarem que, com a implementação de outros dispositivos, a internação psiquiátrica poderá ser o último recurso a ser utilizado.

Entretanto, outros profissionais continuam se posicionando contrários ao modelo hospitalocêntrico, como o evidenciado na fala da psicóloga Suzana, pontuando que, em Joinville, também houve retrocessos, mas que continuam caminhando dentro da proposta de reforma.

Acho que aqui em Joinville a gente teve alguns retrocessos, mas eu acho que continua avançando, a questão da gente não ter um hospital psiquiátrico contribui muito, pra acelerar a questão da Reforma Psiquiátrica. Você acha que contribuiu não ter hospital psiquiátrico? Eu acho que contribui, pra você implementar uma Reforma Psiquiátrica sim, porque você mostra outras alternativas, que são possíveis outras alternativas, eu acho que existe ainda uma óptica hospitalocêntrica aqui, apesar de tudo, principalmente com a área da psiquiatria, o que permeia a fala deles é a falta de leitos

\author{
${ }^{12}$ Desinstitucionalização: \\ é entendida pelas \\ múltiplas formas de tratar \\ o sujeito em sua \\ existência e em relação \\ com as condições \\ concretas de vida. Um \\ processo de \\ desconstrução, de \\ desmontagem, que não \\ se restringe à \\ reestruturação de \\ técnicas, de serviços, de \\ novas terapias, mas sim \\ um processo ético- \\ estético, de \\ reconhecimento do \\ sujeito de direitos. \\ Desinstitucionalização é \\ um processo ético \\ porque, em suma, \\ inscreve-se em uma \\ dimensão contrária ao \\ estigma, à exclusão, à \\ violência. É manifestação \\ ética, sobretudo, se \\ exercitada quanto ao \\ reconhecimento de \\ novos sujeitos de direito, \\ de novos direitos para os \\ sujeitos, de novas \\ possibilidades de \\ subjetivação daqueles \\ que seriam objetivados \\ pelos saberes e práticas \\ cientificas; e inventa - \\ prática e teoricamente - \\ novas possibilidades de \\ reprodução social desses \\ mesmos sujeitos \\ (Amarante, 2003c).
}


psiquiátricos... Então o avanço que a gente teve com a construção, implantação do CAD, ela fica em segundo plano, porque primeiro vem a falta de leito.... é claro que nem todo profissional tem essa fala, mas dentro da ala psiquiátrica, da área da psiquiatria, a fala é esta, então, eu acho que a gente tem avanços e retrocessos... (Psicóloga Suzana)

Defende, enfaticamente, que não há necessidade de mais leitos psiquiátricos, que a utilização desse recurso de internação tem sido demasiada, e aponta que, com isso, os profissionais não pensam em outras alternativas.

Salienta, também, que mesmo dentro do CAPS a visão hospitalocêntrica se faz presente, e muitas vezes é defendida como recurso principal, o que dificulta implementar a Reforma, pois não sabem lidar com a sintomatologia e a crise:

Só que a gente ainda não tem aquela noção da ideologia de que realmente um CAD pode segurar a crise, que você pode trabalhar com o familiar, com o usuário... é muito medo da responsabilidade, então eu internar parece... esta coisa da proteção...Para os técnicos? É para os técnicos... bom eu percebo assim... (Psicóloga Suzana)

Então, focando a questão da internação hospitalar, sua centralidade no discurso é hegemônica e tida como recurso terapêutico principal; contudo é claro que existem resistências e abertura à implementação de outros dispositivos que viabilizem e garantam a atenção psicossocial.

A profissional Acácia, referindo-se ao trabalho desenvolvido pelas equipes de saúde mental, aponta para certa acomodação por parte dos profissionais. Reconhece o processo de medicalização, a dificuldade de se manter a porta aberta e fazer a reabilitação psicossocial, mesmo dentro do CAPS, vista a práxis dos membros das equipes.

Pensando assim da gente estar atendendo o paciente psiquiátrico, de estar evitando a internação, a institucionalização, eu não vejo isto, claro que eu não estou pensando no $C A D$, estou falando daquelas equipes que estão na rede, que elas tem mais de 18 anos de organizadas, eu acho que estas equipes ela não conseguiram trabalhar no sentido da Reforma, de evitar a internação, elas não estão atendendo a demanda, eu acho que estas equipes se protegeram... Eu acho que a gente agora, neste sentido não estamos conseguindo fazer a reforma, a gente está medicalizando muita gente. E no CAD o psiquiatra vem, atende e vai embora, não se envolve, quer dizer temos aqui um CAD e um ambulatório, os outros profissionais fazem a proposta da reabilitação social do CAD e o psiquiatra faz ambulatório... (Psicóloga Acácia)

Destaca Acácia, com muita propriedade, e nós corroboramos com ela, que os embasamentos teóricos correlacionados com a prática, diante da realidade caótica em que se vive, são relegados. Reforça que não há fóruns de discussão e que faltam compromisso e comprometimento, por parte dos profissionais, com este processo social complexo. "A gente não tem fórum de discussão de reforma psiquiátrica e luta antimanicomial!!! E no Dia Nacional de Luta Antimanicomial só o CAD defendeu a bandeira! Então eu acho esses profissionais muito descompromissados com a reforma, por isso a gente não avançou muito até agora..." (Psicóloga Acácia).

As expectativas de Acácia e Suzana são fundamentadas em suas experiências e persistência no embate e no desejo de romper com o modelo asilar, de desconstruí-lo e de entender e ver a loucura com outro olhar. Fica evidente certa alienação, falta de compromisso profissional e diretriz política institucional. A reforma psiquiátrica acaba sendo reforma de modelo, focalizada na dimensão técnicoassistencial, tendo suas outras dimensões relegadas, negadas ou não compreendidas.

Refletir a prática para nós é algo muito distante. As coisas ainda parecem vagas, talvez nem todos tenham esta necessidade. Refletindo a prática, nós percebemos aonde estamos, um passo a frente, um passo atrás... Quais os pontos que a gente não está olhando, se 
precisa mudar o foco, que caminho a gente pegou acreditando que era o melhor, mas enfim.... não era!!! Naquele momento em 1980 ou 1990, era o melhor, mas hoje olhando, não!!! A gente até defendeu uma coisa, mas aconteceu outra... Acho que não é culpa de alguém e sim de todos nós, dos profissionais, do posicionamento político, infelizmente a gente não troca, não se reflete, não se conhece... Se a gente nem sabe o que pensa, como vai querer saber do outro? (Psicóloga Acácia)

\title{
Desconstruir e reconstruir o quê?
}

A dimensão teórico-conceitual é apontada, na fala de Camila, como sendo um nó nesse processo; ela expressa, de forma clara e profunda, o viés que vem perpassando as bases teóricas conceituais, apontando certa conotação de esvaziamento político-ideológico:

Eu acho que Joinville começou já reformando, por que ele o hospital que tinha antigamente, quando a gente começou com o projeto, ele não existia mais, e nós não colocamos nunca o hospital no projeto... eu acho que Joinville já começou fazendo de uma forma diferente, já entrou no processo de reforma, esta reforma foi se construindo já reformada, se construiu diferente... (Terapeuta Ocupacional Camila)

E continua admitindo que, mesmo começando desse jeito, reformando, construindo diferente, falta um fato que realmente marque o processo no município; cita outras experiências, como o fechamento de hospitais psiquiátricos, e acrescenta:

\begin{abstract}
Eu acho que é isso mesmo, a gente não precisou desconstruir nada.... então, todo mundo que entrava, precisava ter uma caricatura assim do que era o hospital, construído daquele jeito, para poder desconstruir e fazer outra coisa, e aqui foi em cima de idéias, eu trazia pro pessoal as falas, coisas lá do Juquery... Então eu acho que Joinville não tem muito essa cultura da reforma, até por causa disto... ao mesmo tempo que é boa é uma coisa ruim.... pois como a gente não tinha hospital, não tinha profissionais e acabou demorando mais. (Terapeuta Ocupacional Camila)
\end{abstract}

Revela, em sua opinião, que não houve uma bandeira de luta, nem necessidade de maiores confrontos políticos e ideológicos como em outros municípios: "aqui foi em cima de idéias", idéias de outro modelo de assistência.

Entretanto, o discurso "a gente não precisou desconstruir nada" aponta para o cerne principal, que o saber/poder psiquiátrico não precisa ser desconstruído, está posto, dado como acabado, pronto, científico. O que revela e demonstra que a ciência psiquiátrica, sua epistemologia e ideologia, por não serem compreendidas em sua constituição, foram relegadas a outros planos, ficando o foco de atenção voltado ao modelo assistencial e administrativo.

O não identificar, ter clareza e consciência sobre o que se luta, parece ser um grande nó no processo social complexo e, devido à falta de conhecimento mais aprofundado da história e das bases científicas que sustentavam e sustentam o tratamento dispensado aos loucos, luta-se às cegas por reformas administrativas, técnicas terapêuticas e legais.

Precisamos desconstruir, sim, o tempo todo: as relações de poder, o mandato social dos técnicos (Basaglia, 2005; Basaglia et al., 1994), o jeito de compreender o manicômio que existe dentro de cada um, e resgatar a história da loucura e suas formas de tratamento, legitimada pela psiquiatria, pois há um interdito em sabê-la (Saraceno, 2001).

Lobosque (2006) salienta sua preocupação com certo esvaziamento/esfriamento dos novos técnicos, que não mais militam no movimento de luta antimanicomial; que anteriormente nos serviços substitutivos havia certo entusiasmo e paixão, que não raramente deram lugar a um funcionamento rotineiro e a uma posição de certa passividade, conformidade e encolhimento no campo da interlocução. 
Amarante (2003a) alerta sobre a descaracterização, 'capsização' e 'inampsização' da reforma psiquiátrica, pois o que se espera é "que supere a noção de uma simples reforma administrativa ou técnica do modelo assistencial psiquiátrico", que se entenda sua complexidade e abrangência (p.48).

Assim, cabe ressaltar que o modelo asilar e suas técnicas seguem com certa hegemonia, e precisam ser desconstruídos sistematicamente; por isso exercitar a liberdade e a democracia são conquistas árduas e cotidianas. É necessário romper com o manicômio que existe dentro de cada um, independente do lugar de ação, seja ele um hospital, um CAPS, uma oficina de geração de renda, uma moradia, ou num posto de saúde, entre outros.

\section{O discurso dos usuários centrado na terapêutica: chega de hospício!!!}

Os usuários entrevistados, quando abordados sobre esse processo, demonstram e focalizam a atenção na terapêutica, no atendimento em si, na convivência; reconhecem que os cuidados foram ampliados pela atuação das equipes e do CAPS (CAD), o qual é sentido como um espaço diferenciado de acolhimento, emancipação, "de salvação". Vejamos o discurso de Augusto:

O CAD é a minha, é a nossa salvação, dos pacientes.... Ah!! tem muita diferença, lá no hospital, eles faz experiência, como se a gente fosse cobaia, dão um remédio, dão outro, vai aumentando, aumentando, vai tirando....Aqui posso conversar.... Olha tem pacientes que necessitam de medicamentos especiais, mais caro, que foi falado naquela reunião, grupo de autoajuda. Olha na integração dos familiares, pra acompanhar de perto o paciente e saber qual a doença que a pessoa tem... Eu notei diferente foi um movimento na pracinha ali na rua central, mas eu não me senti bem ali... Por que? ah!! muita gente esquisita, risos... (Augusto, usuário)

Outros destaques de Augusto foram referentes: a uma comemoração na praça no Dia Nacional de Luta Antimanicomial, às reuniões do grupo de autoajuda, à participação dos familiares e, sobretudo, à defesa ao sujeito que padece de sofrimento mental, em sua condição de ser no mundo.

Débora, outra usuária, faz críticas à unidade de psiquiatria mesmo dentro do hospital geral, pois o modelo é asilar, os horários são rígidos, há falta de respeito com os usuários e o abandono familiar é notório.

Eu considero o Hospital Regional um hospício! A pessoa sai louca de verdade, minha família me abandonou!... Um olha de jeito estranho, outro empurra, o outro bate, outro diz: vai pro chuveiro... Então, a pessoa acaba saindo de lá louca, eu não sei como não saí louca de lá, é preciso acabar com tudo isto!!!! (Débora, usuária)

Assim como a fala de Augusto, Débora aponta que a forma de acolhimento e tratamento, mesmo dentro de uma unidade de psiquiatria, é manicomial, de controle, de violência e de segregação, "um hospício!" Ele sentia-se como uma "cobaia"; ela, que estava numa fábrica de enlouquecer, "é preciso acabar com tudo isto", ou seja, romper, desconstruir o modelo asilar.

Débora, em seu discurso, tem um tom polêmico e de indignação, pois sua vivência perpassa a dura realidade, ainda enfrentada pela pessoa que padece de sofrimento mental, ou seja, invasão, humilhação, controle e privação de liberdade. Em outra fala, fazendo uma comparação entre o hospital e o CAPS/CAD, reflete que a rede de atenção possibilita um espaço de liberdade:

E parece que tem bastante recursos que antes Joinville não tinha, depois que fechou aquele que esqueço o nome (Hospital Schoereder) ${ }^{13}$, aí abriram um novo recurso, (CAD) vamos ver se vai dar certo. Aqui temos mais liberdade. Liberdade pra quê? Liberdade pra andar, pra escolher o que se quer fazer, se não quer fazer também não precisa... Começa a fazer uma coisa, aí faz outra coisa, não faz mal. Os profissionais incentivam e cada um vai fazendo o que dá conta de fazer. (Débora, usuária) 
Destacamos o toque sutil na fala de Débora, "vamos ver se vai dar certo", pois pode ser diferente ou se tornar igual ao referido hospital, "... um hospício!". Fazemos nossa essa expectativa!

\section{Considerações finais}

A rede de atenção psicossocial em Joinville/SC vem se constituindo, lentamente, com avanços e conquistas que referendam seu modelo e sua práxis.

Os relatos fazem parte da realidade do município, e revelam que o discurso está permeado de compreensões e tensões próprias do processo social complexo de Reforma Psiquiátrica num campo abrangente de saúde mental imbricado nas políticas públicas.

Nessa trajetória da implementação da rede de atenção psicossocial, o município teve o privilégio de contar com a participação de profissionais envolvidos nos primeiros momentos da luta antimanicomial profissionais com formação mais aberta, questionadora, o que, aliado à visão de mundo e postura ética, possibilitou dar certa direção política às propostas de saúde mental.

A compreensão, o confronto e a defesa em prol de implementar ações que desconstruam o modelo asilar ficam evidenciados em alguns discursos, que tendem a ser mais polêmicos e políticos. Sendo esses os discursos que movimentam os bastidores, que buscam alternativas e articulam o embate necessário.

Porém, fica evidente certo viés da (in)compreensão desse processo social complexo, confundido como reforma do modelo de assistência, como sinônimo de melhores condições de assistência e de novas técnicas desenvolvidas, denotando certa redução da dimensão teórico-conceitual, tão importante num processo de questionamentos e críticas às bases científicas da ciência médica psiquiátrica.

A dimensão teórico-conceitual, que sustenta e oxigena esse processo, mostra-se relegada a um segundo plano, seja pela incipiente reflexão entre a teoria e a prática, ou por exigir dos técnicos envolvidos a recusa do mandato social.

Entretanto, posicionar-se em defesa de uma "Sociedade sem Manicômios", por uma rede de atenção psicossocial substitutiva, inclusiva e cidadã, é uma tarefa desafiadora que exige: romper com velhos paradigmas, olhar a loucura em sua singularidade, possibilitar ao sujeito que sofre, além dos cuidados, um novo estatuto, o de ser cidadão, o protagonista de sua história.

Podemos, então, constatar a realidade acima referida no município de Joinville-SC, o que nos permite pensar que outros municípios enfrentam realidade semelhante na implementação desse processo social complexo de Reforma Psiquiátrica.

\section{Colaboradores}

Os autores Maria Lúcia da Silva Bueno e Sandra Caponi participaram, igualmente, de todas as etapas de elaboração do artigo. 


\section{Referências}

ALVERGA, A.R.; DIMENSTEIN, M. A loucura rompida nas malhas da subjetividade. In: AMARANTE, P. (Org.). Archivos de saúde mental e atenção psicossocial 2. Rio de Janeiro: Nau Editora, 2005. p.45-66.

AMARANTE, P. Saúde mental e atenção psicossocial. Rio de Janeiro: Fiocruz, 2007.

A (clínica) e a reforma psiquiátrica. In: (Org.). Archivos de saúde

mental e atenção psicossocial. Rio de Janeiro: Nau Editora, 2003a. p.45-66.

Saúde mental, políticas e instituições: programa de educação à distância. Rio de Janeiro: Fiotec/Fiocruz/Ead, 2003b. v.2, v.3.

O homem e a serpente: outras histórias para a loucura e a psiquiatria. Rio de Janeiro: Fiocruz, 2003c.

Loucos pela vida: a trajetória da reforma psiquiátrica no Brasil. Rio de Janeiro: $\overline{\text { Fiocruz }}, 2000$

Asilos, alienados, alienistas: uma pequena história da psiquiatria no Brasil. In: p.73-84.

(Org.). Psiquiatria social e reforma psiquiátrica. Rio de Janeiro: Fiocruz, 1994.

BASAGLIA, F. Instituições da violência. In: AMARANTE, P. (Org.). Escritos selecionados em saúde mental e reforma psiquiátrica. Rio de Janeiro: Garamond, 2005. p.91-132.

BASAGLIA, F. et al. Considerações sobre uma experiência comunitária. In: AMARANTE, P. (Org.). Psiquiatria social e reforma psiquiátrica. Rio de Janeiro: Fiocruz, 1994. p.1140.

BIRMAN, J; COSTA, J.F. Organização de instituições para uma psiquiatria comunitária. In: AMARANTE, P. (Org.). Psiquiatria social e reforma psiquiátrica. Rio de Janeiro: Fiocruz, 1994. p.41-72.

BUENO, M.L.S. A construção do discurso dos atores sociais envolvidos com o processo de Reforma Psiquiátrica: um estudo do município de Joinville/SC. 2006. Dissertação (Mestrado) - Centro de Ciências da Saúde, Universidade Federal de Santa Catarina, Florianópolis. 2006.

DESVIAT, M. A reforma psiquiátrica. Rio de Janeiro: Fiocruz, 2002.

GILL, R. Análise do discurso. In: BAUER, M.W.; GASKELL, G. (Orgs.). Pesquisa qualitativa, com texto, imagem e som: um manual prático. Petrópolis: Vozes, 2002. p.238-55.

LOBOSQUE, A.M. Um desafio a formação: nem a fuga da teoria, nem a recusa da invenção. In: (Org.). Belo Horizonte: ESPMG, 2006. p.33-44.

MINAYO, M.C.S. O desafio do conhecimento: pesquisa qualitativa em saúde. 7.ed. São Paulo/Rio de Janeiro: Hucitec/Abrasco, 2000.

ORLANDI, E.P. Análise de discurso: princípios \& procedimentos. São Paulo: Editora Pontes, 2000.

PAULIN, L.F.; TURATO, E.R. Antecedentes da reforma psiquiátrica no Brasil: as contradições dos anos 1970. Hist., Cienc., Saude - Manguinhos, v.11, n.2, p.241-58, 2004.

PORTOCARRERO, V. Arquivos da loucura: Juliano Moreira e a descontinuidade histórica da psiquiatria. Rio de Janeiro: Fiocruz, 2002.

ROTELLI, F.; LEONARDIS, O.; MAURI, D. Desinstitucionalização, uma outra via. In: NICÁClO, F. (Org.). Desinstitucionalização. 2.ed. São Paulo: Hucitec, 2001. p.17-59.

O inventário das subtrações. In: NICÁCIO, F. (Org). Desinstitucionalização. 2.ed. São Paulo: Hucitec, 2001. p.61-4. 
SARACENO, B. Libertando identidades: da reabilitação psicossocial à cidadania possível. 2.ed. Belo Horizonte/Rio de Janeiro: Instituto Franco Basaglia/Te Cora, 2001.

TENÓRIO, F. A reforma psiquiátrica brasileira, da década de 1980 aos dias atuais: história e conceito. Hist., Cienc., Saude - Manguinhos, v.9, n.1, p.25-59, 2002.

BUENO, M.L.S.; CAPONI, S. La construcción del discurso de los sujetos vinculados al proceso de reforma psiquiátrica - un estudio referente al municipio de Joinville, estado de Santa Catarina, Brasil. Interface - Comunic., Saúde, Educ., v.13, n.28, p.137-50, jan./mar. 2009.

Se trata de situar el discurso de los sujetos vinculados al proceso de Reforma Psiquiátrica en el municipio de Joinville. Es preciso elucidar y desvelar discursos y prácticas pues en la práctica cotidiana se construye el conocimiento y se transforma la realidad. Como camino metodológico utilizamos la pesquisa cualitativa, tipo estudio de caso, realizada por medio de entrevista abierta con guión semi-estructurado. Los sujetos consultados han contribuido con sus experiencias y reflexiones, expresando sus opiniones y convicciones en cuanto al proceso en curso. Las consideraciones finales, basadas en el análisis del discurso, ofrecen críticas puntuales; a veces más polémicas y políticas y otras más conservadoras y tradicionales, revelando cierta distorción y reduccionismo del proceso aunque nuevos espacios van siendo ocupados y las prácticas de algunos profesionales se han alterado.

Palabras clave: Psiquiatría. Salud Mental. Análisis del discurso. 